\title{
Pointing and talk by low-income mothers and their 14-month-old children
}

\section{Citation}

Rowe, M. L. 2000. "Pointing and Talk by Low-Income Mothers and Their 14-Month-Old Children." First Language 20 (60) (January 1): 305-330. doi:10.1177/014272370002006005.

\section{Published Version}

doi:10.1177/014272370002006005

\section{Permanent link}

http://nrs.harvard.edu/urn-3:HUL.InstRepos:17370732

\section{Terms of Use}

This article was downloaded from Harvard University's DASH repository, and is made available under the terms and conditions applicable to Other Posted Material, as set forth at http:// nrs.harvard.edu/urn-3:HUL.InstRepos:dash.current.terms-of-use\#LAA

\section{Share Your Story}

The Harvard community has made this article openly available.

Please share how this access benefits you. Submit a story.

Accessibility 
Pointing and talk by low-income mothers and their 14-month-old children

Meredith L. Rowe

Harvard University Graduate School of Education

Final version for publication in First Language - 2000

RUNNING HEAD: Maternal and child pointing and talk

\author{
Address for Correspondence: \\ Meredith L. Rowe \\ Harvard Graduate School of Education \\ 311 Larsen Hall, Appian Way \\ Cambridge, MA 02140 \\ (617) 495-3546 (phone) \\ (617) 495-5771 (fax) \\ Meredith_Rowe@gse.harvard.edu
}

Portions of this paper were presented at the biennial meeting of the Society for Research in Child Development, Albuquerque, New Mexico in April, 1999, and at the 8th meeting of the International Congress for the Study of Child Language in July, 1999. The data come from a National study of Early Head Start. This work was supported by grant 90YF0009/04 from the Department of Health and Human Services to Catherine Snow, Barbara Alexander Pan, and Catherine Ayoub. I'd like to thank Barbara Alexander Pan and Catherine Snow for their support and extensive comments on earlier drafts of this manuscript. 


\begin{abstract}
This study examines maternal talk and uses of the pointing gesture during interaction with young children in order to uncover the relationship between maternal and child pointing and talk. Forty-five low-income mother-child dyads were videotaped in their homes at child age 14 months. Results indicate that a) mothers and children who talk more point more during interaction, b) the majority of pointing gestures are used to direct the hearer's attention, c) mothers who communicate more with their children view their children as understanding more, d) more educated mothers point more in the context of discussing a joint focus of attention and for conversation-directing purposes. Findings are discussed in terms of the relationship between maternal communicative characteristics and child pointing and talk.
\end{abstract}


Introduction

Communication through gestures is common between adult caregivers and young children. Research with both adults and children indicates that gestures are not redundant with speech but add to the meaning conveyed in speech. Together, speech and gesture relay a coherent message to the listener through two modalities of expression (GoldinMeadow, 1998; McNeil, 1998; Iverson, Capirci, \& Caselli, 1994; McNeil, 1985). In the realm of verbal communication there has been much research focusing on the role of parental speech in child vocabulary development. In regard to the quantity of talk addressed to children, results show that parents who direct more speech to their children have children with larger vocabularies (Hart \& Risley, 1995) and faster vocabulary growth over time (Huttenlocher et al., 1991). Research on individual differences in communication styles has revealed that children of mothers with more directive speech styles tend to have smaller early vocabularies than children of mothers with more expressive speech styles (Nelson, 1973). Furthermore, mothers who communicate more referentially rather than expressively have children with these same tendencies (Hampson \& Nelson, 1993). These findings in the realm of verbal communication urge study of the prevalence, determinants, and consequences of individual differences in maternal uses of nonverbal communication during mother-child interaction.

In the gestural realm, there is relatively little information about variation in the quantity of adult pointing with children and the relationship between pointing and talk within individuals. In addition, there are few studies investigating either mothers' adaptation of gesture use to child age or language abilities, or the relationship between 
maternal pointing and child pointing or speech. One study, however, by Bekken (1989, cited in McNeil, 1992) found that mothers adjusted their gestures in interaction with young children by using primarily concrete deictic gestures instead of the broad range of gestures (e.g., deictic, iconic, metaphoric) they used with other adults. In another study, among a sample of 12 Italian upper-middle class dyads (Iverson, Capirci, Longobardi, \& Caselli, 1999), Iverson and colleagues found that "mothers appear to be using a kind of 'gestural motherese' characterized by fewer and more concrete gestures redundant with and reinforcing the message conveyed in speech (p.19)." That is, maternal gestures directed to young children do not typically add information to speech, in contrast to gestures frequently found in adult-adult interactions (McNeil, 1992). In addition, Iverson and colleagues observed significant relationships between quantity of maternal gesture and child gesture and speech. Interestingly, when the total amount of maternal verbal production was partialed out, these relationships were no longer significant suggesting that the relationship was reflective of the overall communicativeness of the mother. This result builds on findings in the verbal realm that mothers who talk more have children who talk more, by suggesting that the phenomenon is a more general one, where mothers who communicate more (verbally and nonverbally) have children who communicate more.

Studies of infants, whose first communications often take the form of gestures (Locke, Service \& Chandler, 1990; Masur, 1990; Bates, Camaioni, \& Volterra, 1975), shed light on the role of gesture in child language development and early interactions. The most common early gestures used by children are deictic (i.e., establish reference) and include showing, giving, and pointing. While showing and giving tend to emerge 
first and may serve as precursors to pointing (Bates, 1979; Werner \& Kaplan, 1963 as cited in Iverson \& Thal, 1998), pointing is the most frequent deictic gesture between 9-24 months of age (Capirci, Iverson, Pizzuto, \& Volterra, 1996; Iverson, Capirci, \& Caselli, 1994; Masur 1990).

Young children produce pointing gestures beginning around 9 months of age (Masur, 1990; Murphy \& Messer, 1977; Bates, Camaioni, \& Volterra, 1975). Reviewing research on infant comprehension of pointing, Carpenter, Nagell, and Tomasello (1998) conclude that infants develop the ability to follow others' points between 12 and 15 months of age. Although some research shows that under laboratory conditions infants do not fully understand the referential aspects of pointing until a bit later around 15-18 months (Morissette, Ricard, and Decarie, 1995). This ability grows out of two capacities that develop during this same period -- following adult gaze, and fixating on targets rather than the hand used for pointing (Butterworth \& Grover, 1988, 1990 cited in Carpenter, Nagell, and Tomasello 1998).

Children use pointing for a variety of communicative purposes. Early on, around 9-12 months, its primary function is imperative (e.g., to request an adult behavior); somewhat later pointing comes to be used for more declarative purposes (e.g., directing an adult's attention to an object or person) (Masur, 1990; Bates, Camaioni, \& Volterra, 1975). Because pointing for declarative purposes indicates that infants understand others as intentional agents (Carpenter, Nagell, \& Tomasello, 1998), it is frequently studied in relation to child language development and this is the focus of the present study.

Previous research has provided a clear description of development of the pointing gesture and its relationship to speech development in children. Pointing tends to precede 
production of one-word utterances, and gesture-word combinations precede and predict the occurrence of two-word utterances in young children (Goldin-Meadow, 1998; Iverson, Capirci, \& Caselli, 1994). Children between one and two years of age typically do not gesture and speak at the same time (McNeil, 1992). It is during the transition to two-word utterances, when gestures and words are combined, that speech and gesture become an integrated system characterized by semantic and temporal coherence (GoldinMeadow, 1998). Further evidence that gesture and speech are part of the same communicative system is offered by work of Capirci and colleagues (1996) who found that 16 month olds' production of gestures and gesture-word combinations predicted their verbal production four months later. In addition, Harris and colleagues (1995) report a significant association between the onset of child pointing and child comprehension of object names. Furthermore, mothers' provisions of labels in response to child points (Masur, 1982) have been found to predict the number of object names in the children's lexicons. These last two studies suggest an indirect link between amount of child pointing and child vocabulary comprehension and production.

In contrast to the rich literature on mother-child verbal interaction, few studies have approached gesture interactionally. For example, in a study of pointing during mother-child interaction with children ages 9, 14, 20 and 24 months, Murphy (1978) found significant associations between maternal pointing and labeling, particularly at child age 14 months. In addition, she noted an increasing tendency with child age for mothers or infants to combine pointing gestures, yielding what she termed 'pointing strings,' (e.g. one participant successively pointing at different pictures during the book reading session). None of this prior research, however, has considered the interactional 
nature of pointing between mother and child. One question, for example, is whether there are 'pointing sequences,' (e.g. mother and child taking turns pointing at different pictures in a book) and if so, what consequences these types of interactions may have for child lexical development.

Since pointing helps establish joint attention between mother and child (Iverson, Capirci, \& Caselli, 1994), and turn taking by mother and child during joint attention is related to the child's achievement of labeling (Ninio \& Bruner, 1978), particularly where the mother follows the child's lead (Tomasello \& Farrar, 1986; Carpenter, Nagell, \& Tomasello, 1998), study of variation among mothers in nonverbal turn-taking interactions with their children is warranted.

Most of the aforementioned studies of mother-child interaction in the verbal realm, and all of the studies of mother-child interaction in the gestural realm have been carried out with middle-class or upper-middle class mothers. Low-income mothers are an understudied group and little is know about the range of variation among low-income families. Thus, the present study was designed to examine variation in quantity and quality of verbal and nonverbal communication within a low-income sample.

The present study has two goals. First, to describe the uses of the pointing gesture in this understudied population of mother-child dyads. Specific questions addressed are a) how frequently do low-income mothers and their children talk and use the pointing gesture? and b) for what communicative purposes do mothers and their children use the pointing gesture?

The second purpose of the study is to adopt an interactional perspective to investigate whether specific maternal uses of the pointing gesture contribute to child 
gestural uses and child lexical development. Given previous research demonstrating that quantity of child directed speech positively influences child vocabulary development, one hypothesis is that the mere quantity of maternal pointing influences child pointing or lexical development. A second hypothesis is that the purposes for which gestures are used influences child pointing or lexical development. A third hypothesis is that maternal responsiveness to child pointing, either through gesture or speech, influences child lexical development (perhaps by prolonging periods of joint attention). Specific questions posed to investigate these hypotheses include a) does frequency of maternal pointing relate to child pointing or vocabulary production? b) does the communicative intent of maternal pointing relate to child pointing or vocabulary production? and c) does the incidence of pointing sequences relate to child pointing or vocabulary production? Finally, sources of variation in the quantity and quality of maternal pointing gestures in this sample are examined.

\section{Method}

\section{$\underline{\text { Participants }}$}

The participants were 45 low-income mothers and their 14-month-old children ( 25 girls and 20 boys) drawn from a full sample of 146 dyads participating in a longitudinal study on the effectiveness of an Early Head Start program in Brattleboro VT. All mothers were living in Windham County, Vermont, at the time of data collection and qualified for welfare services. The average annual income for the families in the sample is $\$ 13,361$ ( $\mathrm{SD} 7,979)$. Maternal education level ranged from 9 years to completion of a Master's degree, however only three mothers had a bachelors degree or higher. While 
the mothers in the sample are all considered "low-income," their income and education levels vary and are significantly related to one another $(\mathrm{r}=.35, \mathrm{p}<.05)$. Families entered the study either during the mother's pregnancy or sometime before the child's first birthday. All mothers were White native English speakers, with the exception of one native Spanish speaker who also spoke English. Of the 45 children, 28 were first-born and 17 were later-born. The 45 dyads studied are those families in which the focus child reached the age of 14 months by December 31st, 1996. These 45 families are representative of the whole sample of 146 families in regard to mother's education level, marital status, occupation, and ethnic background.

\section{$\underline{\text { Procedure }}$}

All dyads were videotaped at home at child age 14 months. They were provided with bags containing various toys. The first bag contained a picture book, the second bag a toy cooking set with a plastic stove top and pots, and the third bag a toy Noah's Ark with plastic animals. Mothers were instructed to start with the first bag, then move on to the second bag, and finish with the third bag. Ten minutes was allotted for playing, and dyads were not required to get to every bag.

All mothers completed the MacArthur Communicative Development Inventory (CDI) (Fenson, et al., 1994) short-form (Level 1) at child age 14 months. The CDI consists of three sections in which mothers complete checklists of their child's word comprehension, word production, and gesture production. For this study in the gesture section only the item asking whether the child uses the pointing gesture "often," "sometimes," or "not yet" was analyzed. The CDI has been shown to have internal 
consistency, test-retest reliability, as well as concurrent validity based on child performance measures (Fenson, et al., 1994).

Transcription

The videotaped interactions were transcribed using the Child Language Data Exchange System (CHILDES) (MacWhinney, 1991). Transcripts include both verbal and nonverbal behavior by mother and child. The unit of transcription was the verbal or nonverbal utterance, defined as any statement by one speaker bounded by grammatical closure and/or a pause of more than two seconds, or transition in speaker. A second transcriber verified all transcripts to ensure that occurrences of the pointing gesture were transcribed accurately.

\section{Coding \& Analyses}

Two coding systems were applied to the data. First, every occurrence of pointing in the transcripts was coded in CHILDES using the Inventory of Communicative Acts Abridged (INCA-A) speech act coding system (Ninio, Snow, Pan, \& Rollins 1994) a modified version of the system developed by Ninio and Wheeler (1984). Speech act theory presupposes a goal-oriented attitude towards communication, that is, that people interact in specific ways for social purposes (Austin, 1962). The INCA-A system has been used for coding verbal and nonverbal communicative intents expressed by parents and young children (Pan, Imbens-Bailey, Winner, \& Snow, 1996; Snow, Pan, ImbensBailey \& Herman, 1996) and was used here to capture the communicative function of each pointing gesture.

The communicative function of each point, with or without accompanying speech, was coded on two levels. The first level describes the type of social interchange in which 
the dyads were engaged. In these transcripts pointing was used in the context of three types of social interchanges: directing the hearer's attention (DHA), discussing a joint focus of attention (DJF), and negotiating the immediate activity (NIA). The second level of coding captures the specific intent of the point (see Appendix A, for explanations and coding scheme). For example, if the mother says, "what's that?" and points to a toy the child is not currently playing with, this would be coded as directing the hearer's attention by asking a wh-question (e.g., DHA:QN). All communicative functions expressed by the mothers were subsequently categorized as either conversation-eliciting or conversationdirecting (see Appendix B for codes in each group). These categories were developed in order to investigate whether there is a relationship between mothers who use pointing for more conversation-eliciting purposes and child pointing and/or talk.

A second coding system was adopted from Iverson, Capirci, Longobardi and Caselli (1999) to capture the contribution of gesture to the message conveyed by accompanying speech. Their system distinguished gestures that (a) reinforce the verbal utterance (e.g., pointing to a referent while naming it), (b) disambiguate the message conveyed in speech (e.g., pointing to a referent while saying "this" or "there"), or (c) add information not explicit in speech (e.g., pointing to a referent while saying "pretty"). In the present study, every occurrence of pointing accompanied by speech by mother or child was further coded using an adaptation of the Iverson et al. system (See Table 1 below). The purpose of this coding was to try to capture differences in how mothers and children use pointing to bolster or clarify their speech. For example, it may be that some individuals use pointing primarily to reinforce a label of an object, while others use it to 
clarify deictic terms. These potential differences may relate to child uses of pointing and child vocabulary development.

Insert Table 1 about here

Iverson et al. (1999) found that most maternal gestures fell into the "reinforce" category and concluded that this redundancy of information conveyed through gesture and speech constitutes a kind of "gestural motherese" where the mother is adapting her communicative input to the level of the child. Given the differences in culture and social class between the sample in their study and the present study, the codes were applied here to determine if, in this low-income American sample, mothers' gestures make the same contribution to speech as in the Italian upper-middle class sample.

Finally, pointing sequences, defined as mother and child taking turns pointing, were tallied for each dyad in order to investigate the interactional uses of pointing. Engagement in pointing sequences were considered evidence of periods of prolonged joint attention with books/objects. These sequences may reflect routine uses of pointing by mother and child, situations previously shown to promote language development in young children (Ninio \& Bruner, 1978; Snow \& Goldfield, 1983).

\section{$\underline{\text { Reliability }}$}

Reliability of each coding system was assessed on $15 \%$ of the data (seven transcripts). Two trained coders independently coded each occurrence of pointing in the seven randomly chosen transcripts. The simple percentage of agreement among the two coders for the INCA-A codes at the level of social interchange was 76\%, with Cohen's kappa (Bakeman \& Gottman, 1986) of .56. This relatively low Cohen's kappa may be due to the fact that pointing gestures not accompanied by speech are hard to distinguish 
as either DHA or DJF. At the level of specific intent (i.e., conversation-eliciting or conversation-directing), the percentage of agreement among the two coders was $93 \%$, with Cohen's kappa of .75. The percentage of agreement between the two coders for the coding system adapted from Iverson and colleagues (1999) was 85.2\%, with Cohen's kappa of .81 .

\section{Results}

The aim of this study was twofold: first to describe the uses of the pointing gesture in a low-income sample of mother-child dyads, and second to investigate whether specific maternal uses of the pointing gesture relate to child uses of gesture and/or child lexical development. The results are divided into three sections. First, results are presented on the amount of maternal and child pointing and talk and the communicative intent of maternal and child pointing gestures. The second section focuses on whether frequency or communicative intent of maternal pointing and/or talk relates to child pointing and/or talk, and whether frequency of pointing sequences relates to child talk. Finally, results investigating the role of maternal education in explaining the variation in maternal communicativeness are presented.

\section{Uses of the pointing gesture}

Automated analysis of transcripts yielded measures of maternal and child spontaneous language production and pointing. Descriptive statistics for these measures, maternal education, and the CDI are presented in Table 2. 


\section{Maternal pointing and talk}

Despite the relatively homogeneous nature of the sample in terms of income and ethnicity, there is wide variation in the amount of maternal talk (measured as word tokens per 10 minutes) and pointing addressed to children. No significant differences in the amount of maternal pointing or talk addressed to first-born and later-born children were found. On average, ten percent of maternal utterances were accompanied by the pointing gesture. The average number of maternal points was 15 , with a range from 0 to 50 , and the average number of words used was 532.6 with an extremely wide range from 116 to

\section{1,252 (Table 2).}

\section{Child pointing and talk}

By age 14 months there is already substantial variation in the quantity of children's pointing and talk. On average, 33 percent of child utterances were accompanied by the pointing gesture, with a range from 0 to 100 percent. The average number of child points in the 10-minute interaction was 3.26 with a range from 0 to 17 , and the average number of words used was 5.15 with a range from 0 to 39 (Table 2).

\section{Contribution of gesture to accompanying speech}

Analyses using the coding system adapted from Iverson and colleagues (1999) indicated that only 1 percent of maternal points occurred unaccompanied by speech, compared to 37 percent of child points. The majority of maternal pointing gestures served either to reinforce the message conveyed in speech (57\%) or to disambiguate the message in speech (33\%) (Figure 1). 
The majority (62\%) of child points accompanied unintelligible speech, 12 percent reinforced the accompanying speech, 6.5 percent disambiguated speech, and 17 percent added information to the message conveyed in speech (Figure 2).

Insert Figures $1 \& 2$ about here

\section{$\underline{\text { Communicative function of pointing gestures }}$}

Descriptive statistics on the social interchanges expressed in maternal and child pointing gestures with or without speech are presented in Table 3. Only mothers and children who produced at least one point during interaction were included in the following analyses.

Insert Table 3 about here

Analyses of the social interchanges expressed by points for mothers revealed that, on average, the majority of maternal points was used in the context of directing the child's attention (66\%); a smaller percentage of points was used in the context of discussing a joint focus of attention (19\%) or negotiating the immediate activity (15\%) (Figure 3). Similar analyses of children's points reveal that, on average, the majority was also used in the context of directing the hearer's attention (61\%), with the remaining divided nearly evenly between discussing a joint focus of attention (25\%) and negotiating the immediate activity (22\%) (Figure 4). 
To summarize, there is large variation in the amount of maternal and child pointing and talk in this low-income sample. The majority of maternal and child points were used in the context of directing the hearer's attention or discussing a joint focus of attention and the majority of maternal points reinforced the message conveyed in speech.

Relationships between maternal and child communicativeness

Relationship between maternal pointing, maternal talk, child pointing, and child $\underline{\text { talk }}$

Bivariate analyses revealed positive correlations between pointing and talk within individuals, indicating that mothers and children who talk more also point more (Table 4). It is interesting to note the lack of a significant relationship between dyadic partners in either verbal or nonverbal communication.

Insert Table 4 about here

Scatterplots of the relationship between pointing and talk within individuals are displayed in Figures $5 \& 6$. Visual examination of the relationship between child pointing and child talk (Figure 6) indicated that the positive relationship is concentrated in children who use over five words during the ten-minute interaction. For children who use fewer than five words, there seemed to be no relationship, or possibly a negative relationship, between pointing and talk. Among children who used five or more words 
during the interaction $(\mathrm{n}=15)$ additional analyses to determine whether there was a relationship between maternal communicativeness and child communicativeness showed no significant correlations at this early point in children's communicative development.

Insert Figures $5 \& 6$ about here

$\underline{\text { Relationship between communicative intent of maternal pointing and child }}$ $\underline{\text { communicativeness }}$

Investigation of the relationship between maternal uses of the pointing gesture and child communicativeness revealed a positive yet non-significant relationship between mothers who tend to use pointing in the context of directing their child's attention and child pointing $(\mathrm{r}=0.27, \mathrm{p}=.07)$.

Investigation of the relationship between maternal categories of gestural contribution and child communicativeness revealed a significant positive correlation between maternal points that added information to the message conveyed in speech and child total points $(\mathrm{r}=0.38, \mathrm{p}<.05)$. However, further investigation of this relationship revealed that it was heavily influenced by one outlier dyad. Upon removal of that dyad, the significant relationship disappeared $(\mathrm{r}=.09)$.

Examination of the communicative intent of pointing revealed that mothers, on average, used pointing more for conversation-directing purposes (mean $=13.4$, $\mathrm{SD}=11.16)$ than for conversation-eliciting purposes (mean $=2.38, \mathrm{SD}=2.38)$; however, there was substantial variation around the means. Correlational analyses failed to show a 
significant relationship between either maternal conversation-eliciting or conversationdirecting pointing and child pointing or talk.

Correlational analyses of maternal uses of the pointing gesture and the children's CDI scores revealed several interesting relationships. Children's vocabulary comprehension was significantly, though moderately, positively correlated with maternal points that direct the hearer's attention $(\mathrm{r}=.33, \mathrm{p}<.05)$, but not with those involved in discussing a joint focus of attention. This pattern was somewhat surprising given research showing a link between talk during joint attentional episodes and child vocabulary development. One possible explanation for this association is that the use of pointing (with or without speech) to re-direct a child's attention may facilitate the child's understanding of the adult's intent, and is then less disruptive to the child's current attentional focus than a solely verbal redirection would be. Or it may simply be that points that direct the child's attention are used at a time when the child is not currently engaged or focused on an activity. Children's vocabulary comprehension (CDI) was also moderately correlated with maternal points that reinforce the message conveyed in speech $(\mathrm{r}=.33, \mathrm{p}<.05)$, possibly suggesting that mothers who view their 14-month-old children as having large vocabularies believe they still need additional support (e.g. pointing) in order to understand oral language.

$\underline{\text { Relationship between pointing sequences and child pointing and talk }}$

The occurrence of pointing sequences was relatively infrequent. Of the 31 dyads where both mother and child pointed at least once, 18 dyads participated in pointing sequences. The range of total pointing sequences in the 10-minute period for these dyads was between 1 and 6 . A significant positive relationship was found between pointing 
sequences and child talk $(r=.44, p<.05)$, indicating that the use of the pointing gesture successively by mother and child around an object of joint attention may be conducive to child verbal production.

\section{$\underline{\text { CDI \& Maternal Education }}$}

Results from the CDI showed that nearly all mothers (43 of 45) reported that their children use the pointing gesture "often" or "sometimes." Only two mothers reported that their children are not yet using the pointing gesture. It was not expected that all children who had begun pointing would use the pointing gesture during the 10-minute period. However, it is worth noting that the children of the two mothers who reported they were not yet pointing were among the 13 children who did not point at all during the observation period. This result provides some indication of the accuracy of maternal report on this measure, though of course a longer observation period would help to provide further evidence for this claim.

A substantial amount of variation was found in maternal pointing and talk in this sample. Additional analyses were conducted to determine whether variation in maternal communicativeness was associated with maternal education or age and with maternal estimation of their child's vocabulary.

Insert Table 5 about here

Correlational analyses revealed significant positive relationships between maternal education and quantity of maternal talk $(\mathrm{r}=.35, \mathrm{p}=.02)$ and maternal pointing $(\mathrm{r}=.32, \mathrm{p}=.03)$. Maternal education was also significantly positively related to maternal 
points used in the context of discussing a joint focus of attention $(\mathrm{r}=.42, \mathrm{p}=.004)$ and maternal points used for conversation-directing purposes $(\mathrm{r}=.38, \mathrm{p}=.01)$. Maternal age was significantly positively associated with maternal education $(\mathrm{r}=.38, \mathrm{p}=.009)$ and almost reached significance with maternal talk $(r=.28, \mathrm{p}=.06)$. When maternal age, which has been shown to serve as a proxy for education in some samples, was partialed out the relationships between education and quantity of maternal talk and pointing remained positive yet were no longer significant. However, the relationships between maternal education and quality or uses of maternal pointing remained positive and statistically significant at the .05 level. In addition, correlational analyses indicate a significant positive relationship between the CDI comprehension and maternal pointing and talk (Table 5).

\section{Discussion}

The goals of this study were to describe the uses of the pointing gesture in a lowincome sample of mother-child dyads and to determine whether specific maternal uses of the pointing gesture relate to child uses of gesture or child lexical development. The study resulted in four main sets of findings:

- there was wide variation in the amount of maternal and child pointing as well as talk; mothers and children who talk more also point more during parent-child interaction.

- the majority of both mothers' and children's pointing gestures were used to direct the hearer's attention; maternal points often functioned to reinforced the message conveyed in speech.

- children in dyads who engaged in more pointing sequences were more talkative. 
- mothers who addressed more talk and more points to their children viewed their children as understanding more; mothers with higher levels of education used pointing more in the context of discussing a joint focus of attention and for conversation-directing purposes.

\section{Maternal and child uses of the pointing gesture}

There was much variability among mothers and children in the extent to which they talked and pointed during the 10-minute interaction. The strong positive relationship between pointing and talk found within individuals suggests that some mothers and children communicate more overall (i.e., verbally and nonverbally) than others. Therefore, talk and pointing serve as two indicators of overall communicativeness. Among the children, this relationship indicates the relatively equal weight given to gesture and speech in their communicative systems at 14 months. This is to be expected, since most 14-month-old children have not yet transitioned to two-word speech, at which time gesture is found to play a less important role in child communication (Goldin-Meadow, 1998). The findings from mothers are somewhat more surprising because they suggest that the difference among mothers is not just in their verbal facility but in their overall communicativeness.

\section{Communicative function of maternal pointing gestures}

Analyses of the speech act coding results indicated that mothers and children used pointing to engage in social interaction in remarkably similar ways, with the majority of points being used to direct the hearer's attention, followed by those used in the context of discussing a joint focus of attention or negotiating the immediate activity. A positive, yet non-significant relationship was found between maternal points that direct the child's 
attention and quantity of child pointing. This result provides some initial evidence that maternal uses of pointing for specific social interchanges may relate to frequency of child pointing. Future research is needed to examine whether certain activities (i.e., book reading or toy play) provoke specific uses of the gesture by mothers and whether such use relates to child pointing or child lexical development.

The results regarding the contribution of gesture to speech indicate that mothers rarely point without accompanying speech, while approximately one third of 14-monthold children's points are performed without speech. When children did talk while pointing, the talk itself was frequently unintelligible. Paralleling findings by Iverson and colleagues (1999), the majority of maternal points in the present study were used to reinforce or disambiguate the message conveyed in speech rather than to supplement the verbal message with additional information, as is often found in gesture use between adults (McNeil 1992 cited in Iverson et. al., 1999). In addition, while the majority of child gestures were accompanied by unintelligible speech, the second most common category for children was gestures that add to the message conveyed in speech. In these instances it may be that children are relying on gesture to supplement their speech, suggesting that the use of gesture relieves some of the verbal burden. This result is consistent with previous findings of Iverson, Capirci, and Caselli (1994) who conclude that "it may be that the central role of gesture in children's early communication can be ascribed in part to the notion that the production of gesture reduces the demand on developing vocal skills" (p.38). Future analyses should investigate whether this tendency shifts as children's verbal abilities improve. 


\section{$\underline{\text { Relationship between maternal and child pointing and talk }}$}

The lack of a statistically significant relationship between maternal pointing and child pointing or talk is interesting, as it was expected that mothers who point more would have children who point and/or talk more and vice-versa. The relationship between maternal and child pointing was, however, positive in direction, and subsequent analyses of pointing sequences and child talk revealed a statistically significant positive relationship. One interpretation of this finding is that it provides further support for the premise that gesture and speech are part of the same system and reflects a level of overall individual communicativeness. In addition, the fact that children in dyads who engaged in more pointing sequences included children who used more words during the interaction is consistent with findings that maternal referencing which follows the child's focus of attention is positively related to child lexical development (Tomasello \& Farrar, 1986; Carpenter, Nagell, \& Tomasello, 1998). This concurs with findings that turntaking (verbal or nonverbal) during joint attentional episodes promotes lexical development by offering routine predictable situations for the child to use language (Ninio \& Bruner, 1978; Goldfield \& Snow, 1983). In order to further understand the role of pointing sequences in interaction and child vocabulary development, future analyses should investigate the particular types of situations in which pointing sequences occur and the associated language use.

\section{Maternal education and maternal report of child comprehension}

While the primary purpose of this study was to describe the quantity and quality of pointing and talk in a low-income sample, some of the results here are similar to those found in other studies with middle or upper-middle class samples and deserve mention. 
More specifically, the proportion of maternal utterances accompanied by the pointing gesture in this study $(10 \%)$ is very similar to findings from other studies (Iverson et al., 1999; Shatz, 1982), yet in the current study there was a range from 1 to 32 percent, more variability than was found in previous research with middle to upper-middle class samples. In addition, the fact that the majority of maternal points were used to reinforce the message found in speech replicates the findings by Iverson and colleagues in their upper-middle class Italian sample. While the settings and tasks differed across studies, these similarities in findings suggest that the quantity and quality of pointing during mother-child interaction may not be so culturally specific.

The results of the present study highlight several factors associated with variation within in communicativeness among low-income mothers. In regard to quantity of communication, maternal education was associated with maternal talk and pointing, and maternal age was positively associated with maternal education and maternal talk. However, when maternal age is controlled for, the relationship between maternal education and maternal communicativeness, while still positive, is no longer significant. In addition, maternal education within this sample is associated with the communicative functions for which mothers use the pointing gesture, even when controlling for age. First, the more educated mothers in the sample used pointing more in the context of discussing a joint focus of attention. This finding is not surprising, as interactions with children around a joint focus of attention are situations shown to be helpful to the child's language development. On the other hand the result that more educated mothers use pointing more for conversation-directing purposes was not expected. The majority of conversation-directing communicative functions in this study consisted of requests or 
propositions, prohibitions, or declarative statements. Previous research on verbal interaction has shown a negative relationship between highly directive mothers and children's rate of language development (Barnes, Gutfreund, Satterly, \& Wells, 1983). In addition research across social classes has found conversation-eliciting utterances to be more prominent in upper-middle class samples than in working class samples (HoffGinsberg, 1991). Therefore it might be expected that even within this relatively lowincome sample, the more educated mothers would produce more conversation-eliciting, rather than directing, communicative functions (verbal or nonverbal). We need more research to understand the positive or negative effects of using conversation-eliciting versus conversation-directing styles with children from various backgrounds.

The finding that mothers who pointed more and talked more viewed their children as understanding more (as reflected in the CDI checklist) highlights the difficulty in determining who is influencing whom in dyadic interaction. For example, it may be that mothers who communicate more have a better understanding of their child's verbal knowledge. Or it may even be that maternal pointing and talk helps children's verbal comprehension. The data in the present study, however, do not speak to this issue. On the other hand, it is possible that children who convey the impression that they understand more may elicit more talk and pointing from their mothers. This final hypothesis supports the argument by Bekken and Iverson and colleagues that the quantity of maternal gestural communication directed to the child is fine-tuned to the child's comprehension level. Based on the results of the current study, however, we can only present this significant association, we cannot draw any conclusions about directions of potential influences. 


\section{Conclusions}

In sum, the findings reported in this study concur with and expand upon previous results on the use of gesture during mother-child interaction. The main findings include that a) mothers and children who talk more also point more during interaction, b) the majority of maternal and child pointing gestures are used to direct the hearer's attention, and the majority of maternal points reinforce the message conveyed in speech, c) although there is no direct relationship between maternal pointing and either child pointing or child talk, dyads who participate in more pointing sequences have children who talk more and vice versa, d) mothers who view their children as understanding more address more talk and more points to their children, and e) mothers with higher levels of education use pointing more in the context of discussing a joint focus of attention and for conversation-directing purposes.

This study was limited in that it looked at dyads at only one point in time. Future analyses will look at additional data that are being collected on the same dyads at child ages 24 and 36 months in order to investigate maternal influences on child growth over time in gesture and vocabulary use, as well as possible child influences on maternal communicativeness. 


\section{References}

Austin, J. (1962). How to do things with words (2 ${ }^{\text {nd }}$ Ed.). Cambridge, MA: Harvard University Press (pp. 1-38, 109-20).

Bakeman, R., \& Gottman, J.M. (1997) Observing interaction ( $2^{\text {nd }}$ edition). Cambridge, UK: Cambridge University Press.

Barnes, S., Gutfreund, M., Satterly, D., \& Wells, G. (1983). Characteristics of adult speech which predict children's language development. Journal of Child Language, $\underline{10}, 65-84$.

Bates, E. (1979). Intentions, conventions, and symbols. In E. Bates (Ed.), The emergence of symbols: Cognition and communication in infancy. New York: Academic.

Bates, E., Camaioni, L. \& Volterra, V. (1975). The acquisition of performatives prior to speech. Merrill-Palmer Quarterly, 21. 3.

Bekken, K. (1989). Is there "motherese" in gesture? Ph.D. dissertation., Department of Psychology, University of Chicago.

Butterworth, G., \& Grover, L. (1988). The origins of referential communication in human infancy. In L. Weiskrantz (Ed.), Thought without language. Oxford: Clarendon.

Butterworth, G., \& Grover, L. (1990). Joint visual attention, manual pointing, and preverbal communication in human infancy. In M. Jeannerod (Ed.), Attention and performance XIII. Hillsdale, NJ: Erlbaum

Capirci, O., Iverson, J. M., Pizzuto, E. \& Volterra, V. (1996). Gestures and words during the transition to two-word speech. Journal of Child Language, 23, 645-73. 
Carpenter, M., Nagell, K., \& Tomasello, M. (1998). Social cognition, joint attention, and communicative competence from 9 to 15 months of age. Monographs of the society for research in child development, $\underline{n} .255, \mathrm{v} 63, \mathrm{n} .5$.

Fenson, L., Dale, P.S., Reznick, J.S., Bates, E., Thal, D.J., \& Pethick, S.J. (1994). Variability in early communicative development. Monographs of the Society for Research in Child Development, n.242,v.59,n.5.

Goldin-Meadow, S. (1998). The development of gesture and speech as an integrated system. In J. Iverson \& S. Goldin-Meadow (Eds.) The nature and functions of gesture in children's communication. New Directions for Child Development (no. 79). San Francisco: Jossey-Bass.

Hampson, J. \& Nelson, K. (1993). The relation of maternal language to variation in rate and style of language acquisition. Journal of Child Language, 20, 199-215.

Harris, M., Barlow-Brown, F., \& Chasin, J. (1995). The emergence of referential understanding: Pointing and the comprehension of object names. First Language, 15, 1934.

Hoff-Ginsberg, E. (1991). Mother-child conversation in different social classes and communicative settings. Child Development, 62, 782-796.

Huttenlocher, J., haight, W., Bryk, A., Seltzer, M., \& Lyons, T. (1991). Early vocabulary growth: Relation to language input and gender. Developmental Psychology, 27, 236-48.

Iverson, J. M., Capirci, O. \& Caselli, M. C. (1994). From communication to language in two modalities. Cognitive Development, 9, 23-43. 
Iverson, J.M., Capirci, O., Longobardi, E., \& Caselli, M. C. (1999). Gesturing in mother-child interactions. Cognitive Development, 14, 57-75.

Iverson, J.M.,\& Thal D.J. (1998). Communicative transitions: There's more to the hand than meets the eye. In A.M. Wetherby, S.F. Warren, \& J. Reichle (Eds.), Transitions in prelinguistic communication (pp. 59-86). Baltimore: Paul H. Brookes.

Lock, A., Young, A., Service, V. \& Chandler, P. (1990). Some observations on the origins of the pointing gesture. In V. Volterra \& C. J. Erting (Eds.) From gesture to language in hearing and deaf children. New York: Springer-Verlag (p.42-55).

MacWhinney, B. (1991). The CHILDES Project: Computational tools for analyzing talk. Hillsdale, NJ: Erlbaum.

Masur, E. F. (1982). Mothers' responses to infant's object-related gestures: Influence on lexical development. Journal of Child Language, $\underline{9}, 23-30$.

Masur, E. F. (1990). Gestural development, dual-directional signaling, and the transition to words. In V. Volterra \& C. J. Erting (Eds.) From gesture to language in hearing and deaf children. New York: Springer-Verlag (pp.18-30).

McNeil, D. (1985). So you think gestures are nonverbal? Psychological Review, 92, 3.

McNeil, D. (1992). Hand and mind: What gesture reveals about thought. Chicago: University of Chicago Press.

McNeil, D. (1998). Speech and gesture integration. In J. Iverson \& S. GoldinMeadow (Eds.) The nature and functions of gesture in children's communication. New Directions for Child Development (no. 79). San Francisco: Jossey-Bass. 
Morissette, P., Ricard, M., \& Decarie, T.G. (1995). Joint visual attention and pointing in infancy: A longitudinal study of comprehension. British Journal of Developmental Psychology, 13, 163-175.

Murphy, C. M. \& Messer, D. J. (1977). Mothers, infants and pointing: A study of a gesture. In H. R. Schaffer (Ed.), Studies in mother-infant interaction. London: Academic Press. (pp. 325-54)

Murphy, C. M. (1978). Pointing in the context of a shared activity. Child Development, 49 , 371-80.

Nelson, K. (1973). Structure and strategy in learning to talk. Monographs of the

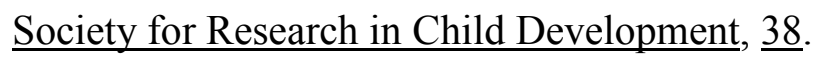

Ninio, A. \& Bruner, J. (1978). The achievements and antecedents of labeling. Journal of Child Language, $\underline{5}, 1-15$.

Ninio, A., Snow, C., Pan, B., \& Rollins, P. (1994). Classifying communicative acts in children's interactions. Journal of Communications Disorders, 27, 157-188.

Ninio, A. \& Wheeler, P. (1984). Functions of speech in mother-infant interaction. In L. Feagans, G. J. Garvey \& R. Golinkoff (Eds.), The origins and growth of communication. Norwood, NJ: Ablex.

Ochs, E. (1979). Transcription as theory. In E. Ochs \& B. Schieffelin (Eds.), Developmental pragmatics. New York: Academic Press, pp. 43-72.

Pan, B. A., Imbens-Bailey, A., Winner, K., \& Snow, C. (1996). Communicative intents expressed by parents in interation with young children. Merrill Palmer Quarterly, $\underline{42}, 248-266$. 
Shatz, M. (1982). On mechanisms of language acquisition: Can features of the communicative environment account for development? In E. Wanner \& L. Gleitman (Eds.), Language acquisition: The state of the art (pp. 102-27). New York: Cambridge University Press.

Snow, C., \& Goldfield, B. (1983). Turn the page please: Situational-specific language acquisition. Journal of Child Language, 10, 551-70.

Snow, C.E., Pan, B.A., Imbens-Bailey, A. \& Herman, J. (1996). Learning how to say what one means. Social Development, $\underline{5}, 56-84$.

Tomasello, M. \& Farrar, M.J. (1986). Joint attention and early language. Child Development, 57, 1454-1463.

Werner, H. \& Kaplan, B. (1963). Symbol formation. New York: Wiley. 
Appendix A: Components of coding communicative function

(Taken from Snow, Pan, Imbens-Bailey \& Herman, 1996)

Definition of social interchanges in transcripts:

Directing Hearer's Attention (DHA)

To achieve joint focus of attention by directing hearer's attention to objects, persons, and events in the environment.

Discussing a Joint Focus of attention (DJF)

To hold a conversation about something in the environment that both participants are attending to, e.g., objects; persons; ongoing actions of hearer and speaker; ongoing events.

Negotiating the Immediate Activity (NIA)

To negotiate the initiation, continuation, ending and stopping of activities and acts; to direct hearer's and speaker's acts; to allocate roles, moves, and turns in joint activities; to evaluate speaker's and hearer's acts as correct or incorrect; or as desirable or undesirable.

Codes used to specify communicative intent of point: 
Maternal and child pointing and talk 
Appendix B: communicative intents classified as Conversation-eliciting or conversation-directing.

(See Appendix A for definition of codes)

Conversation-eliciting:

RQ, EI, EC, EX, EA, FP, QN, YQ, TQ, EQ, AQ, QA, RR,

Conversation-directing:

RP, PF, ST, MK 
Table 1

Description of codes adapted from Iverson et al., (1999) with additional codes developed for the current data.

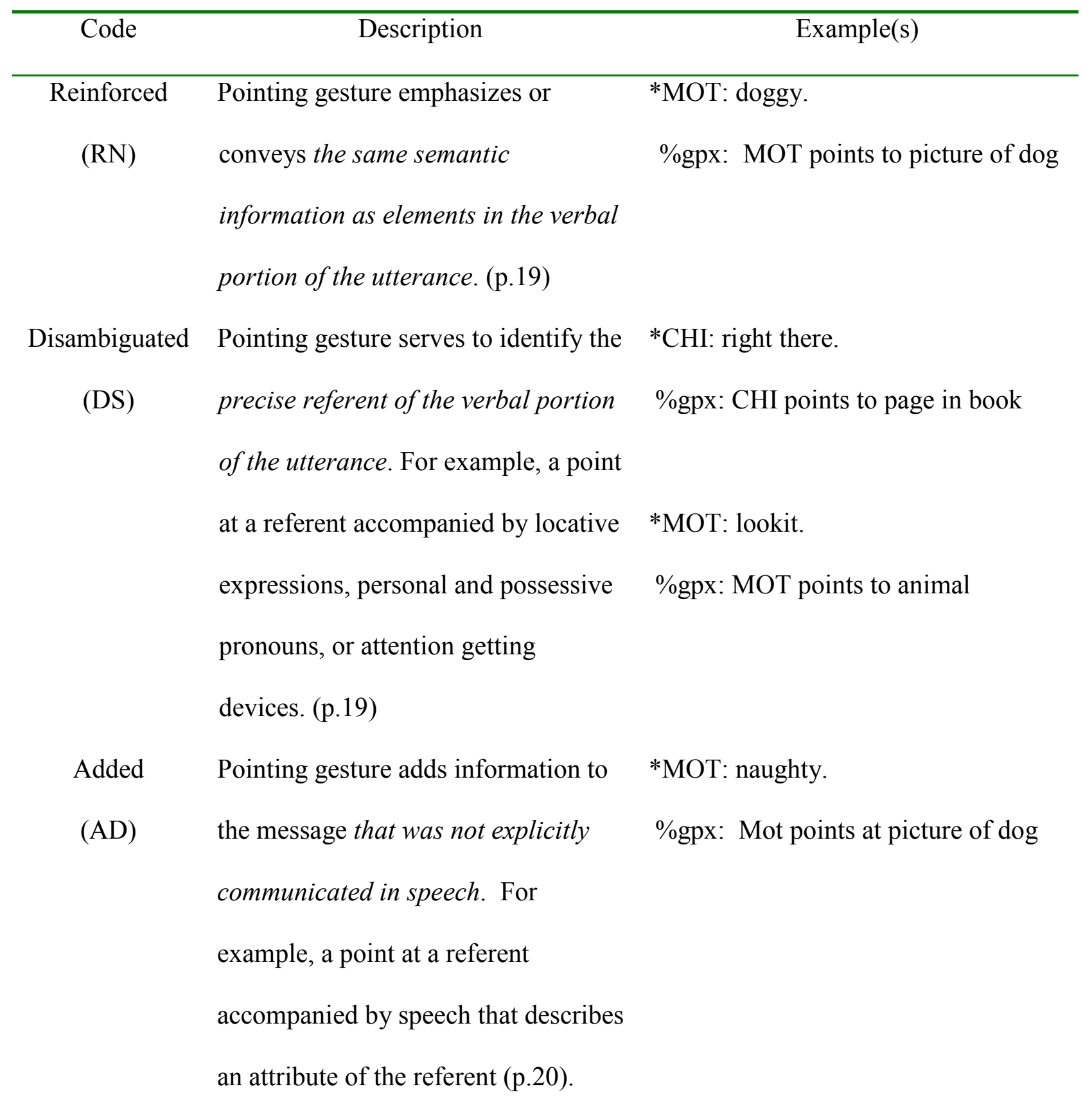

(table continues) 
Maternal and child pointing and talk

\begin{tabular}{cll}
\hline Code & \multicolumn{1}{c}{ Description } & Example(s) \\
\hline *Unintelligible & Pointing gesture is accompanied by & ${ }^{*}$ CHI: xxx. \\
& speech that was unintelligible or not & \%gpx: CHI points at toy elephant \\
(UN) & understood by the transcriber & \\
\hline
\end{tabular}

* This code was added to the system for this study 
Table 2

Measures of pointing, talk, CDI, and maternal education $(n=45)$.

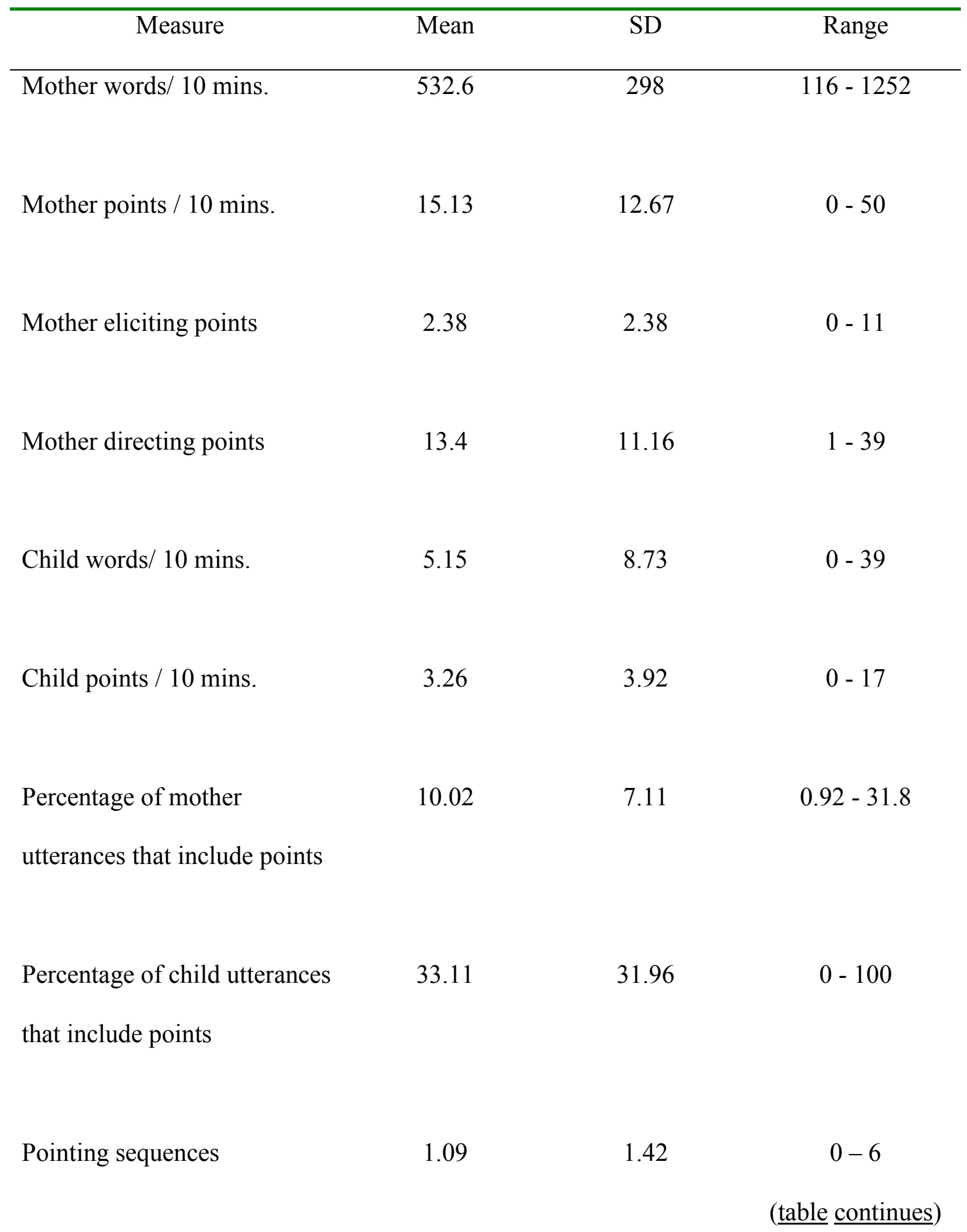




\begin{tabular}{lccc}
\hline \multicolumn{1}{c}{ Measure } & Mean & SD & Range \\
\hline CDI comprehension & 50.02 & 19.27 & $0-87$ \\
CDI production & 12.51 & 9.72 & $0-33$ \\
Maternal education level & 12.02 & 1.62 & $9-18$ years \\
& & & \\
\hline
\end{tabular}


Table 3

Maternal and child uses of pointing to direct the hearer's attention (DHA), discuss a joint focus (DJF), or negotiate the immediate activity (NIA).

\begin{tabular}{lccc}
\hline & DHA & DJF & NIA \\
& Mean (SD) & Mean (SD) & Mean (SD) \\
\hline Mothers $(\mathrm{n}=42)$ & $10(8.8)$ & $2.9(3.5)$ & $2.2(2.9)$ \\
Children $(\mathrm{n}=32)$ & $2.0(2.7)$ & $0.73(1.3)$ & $0.55(1.30$ \\
\hline
\end{tabular}


Table 4

$\underline{\text { Bivariate estimated correlations between maternal and child pointing and talk }(n=45)}$.

\begin{tabular}{|c|c|c|c|c|}
\hline & Mother Words & Mother Pointing & Child Words & Child Pointing \\
\hline \multicolumn{5}{|l|}{ Mother Words } \\
\hline Mother Pointing & $.58 * * *$ & & & \\
\hline Child Words & -.03 & -.03 & & \\
\hline Child Pointing & .02 & .18 & $.64 * * *$ & \\
\hline
\end{tabular}


Table 5

$\underline{\text { Bivariate estimated correlations between maternal pointing and talk and CDI }}$ comprehension.

\begin{tabular}{ll}
\hline & CDI Comprehension \\
\hline Mother Pointing & $.39 *$ \\
Mother Words & $.34 *$ \\
\hline${ }^{*} \mathrm{p}<.05, * * \mathrm{p}<.01$ &
\end{tabular}




\section{Figure Captions}

Figure 1. Total number of maternal points that reinforced (RN), disambiguated (DS), or added (AD) to speech.

Figure 2. Total number of child points that accompanied unintelligible speech (UN), reinforced (RN), disambiguated (DS), or added (AD) to speech.

Figure 3. Total number of maternal points used to direct the hearer's attention (DHA), discuss a joint focus (DJF), or negotiate the immediate activity (NIA) $(n=42)$.

Figure 4. Total number of child points used to direct the hearer's attention (DHA), discuss a joint focus (DJF), or negotiate the immediate activity (NIA) (n=32).

Figure 5. Relationship between maternal pointing and maternal talk $(\mathrm{n}=45)$

Figure 6. Relationship between child pointing and child talk $(\mathrm{n}=45)$ 